\title{
Strategic R\&D Investment Under Information Revelation
}

\author{
FLAVIA CORTELEZZI ${ }^{1}$ AND GIOVANNI VILLANI ${ }^{2}$ \\ ${ }^{1}$ Insubria University and Catholic University of the Sacred Heart, Como, Italy \\ ${ }^{2}$ Faculty of Economics, University of Foggia, Foggia, Italy
}

\begin{abstract}
$R \& D$ projects generally involve multiple phases with or without overlapping. Moreover, the investment is usually made in a phased manner, with the commencement of the subsequent phase being dependent on the successful completion of the preceding phase. The aim of this article is to analyze the equilibrium strategies of two firms competing for a two-stage sequential $R \& D$ investment, when a firm may infer a private signal from the strategy played by the other. Thus, firms must formulate their optimal strategies in a context of imperfect information. We evaluate the resulting compound option with information revelation as an American compound exchange option using Monte Carlo simulations. We then show that different equilibria may arise.
\end{abstract}

\section{Introduction}

In standard real options models the timing of option exercise is generally uninformative. Agents are assumed to be perfectly informed about the fundamental parameters of the option, and the optimal exercise policy is a deterministic function of the state variables. However, there are many realistic situations in which agents are imperfectly informed. Let us consider, for example, an R\&D investment project such as oil exploration (see Paddock et al. [1988] for a general discussion) or the development of a new drug. In the first case, in addition to possessing the standard feature of options, oil exploration possesses important private information externalities. Let us consider, just to give an example, the usual practice in the United States. Due to the leasing practices of the federal government, it is frequently the case that two or more firms lease adjacent tracts of land that may contain an oil deposit (see Hendriks and Kovenock [1989]). Prior to obtaining the lease, each firm has obtained private information about the probability of finding a deposit; that is, each firm obtain a noisy signal of the likelihood of striking oil by combining seismic surveys with in-house expertise. However, the existence and magnitude of the deposit can only be known through drilling. Firms then face a trade-off between the benefits of drilling and potentially obtaining oil earlier and the benefits of waiting for other firms to drill first and reveal information

Address correspondence to Giovanni Villani, Faculty of Economics, University of Foggia, Largo Papa Giovanni Paolo II, 1-71100 Foggia, Italy. E-mail: g.villani@unifg.it 
about the size of the deposit. Therefore, in equilibrium, firms must determine their optimal drilling exercise times in a context of private information and ongoing uncertainty. As far as the development of new drugs, the R\&D project can take more than 10 years to complete. During the whole period, investments in $R \& D$ have to be made without reaping any of the possible benefits of the investment and with a significant probability of terminating the effort for technical or economic reasons. In addition, even for successful efforts, there is uncertainty about the actual costs of development. Furthermore, after the drug has been successfully developed and approved there is substantial uncertainty about the cash flows that it will generate. To evaluate the R\&D project or patent, these cash flows have to be assessed long before they are realized. (There are many other cases not discussed here. Let us consider, among others, the technology of hybrid electric cars in the automotive industry. General Motors stopped its hybrid project in 1998 and restarted it only recently, just after having observed Toyota's success with its hybrid car Prius.)

It is worth noting that in the above-described situations competitive interaction is fundamentally important in the valuation and exercise of real options, especially in order to get a dominant position in the final market product. Moreover, in such cases, agents may impute the private information of others by observing their real options exercise (or lack of exercise) decisions. Several questions arise: How is information conveyed? How do agents determine their exercise strategies?

The aim of this article is to address the above questions by analyzing and quantifying the effect of the irreversible R\&D investment project whose investment/development costs and returns are uncertain, in the presence of information revelation. We derive the optimal investment strategy by applying the real option approach of modern investment theory, evaluating each option as an American compound exchange option through Monte Carlo simulations.

From a methodological point of view, note that $R \& D$ investment can be viewed as an exchange option; that is, a swap of an uncertain investment cost for an uncertain gross project value. This article is strictly related to Margrabe (1978), McDonald and Siegel (1985), Carr (1988, 1995), and Armada et al. (2007). Margrabe (1978) developed a model to price the simple European exchange option (SEEO) to exchange one risky asset for another at maturity date $T$, and McDonald and Siegel (1985) considered the case in which the assets distribute dividends. In a real options context, dividends are the opportunity costs inherent in the decision to defer an investment project. Thus, deferment implies the loss of the project's cash flows (see, Eschenbach et al. [2009] for a close examination on the waiting costs). Carr's (1988) model, building on Margrabe (1978) and Geske (1979), evaluated compound European exchange options (CEEO). This model may be interpreted as a combination of a time-to-build option - that is, a growth option-and an option to exchange an asset for another; that is, an operating option. In addition, Carr $(1988,1995)$ and Armada et al. (2007) provided an approximation to value a simple American exchange option (SAEO). When the asset to be received in the exchange pays large dividend yields, there is always a probability that the American exchange option will be exercised prior to expiration. This means that managers have the time flexibility to start the development phase that gives the opportunity to capture the project's cash flows. With regard to literature on $R \& D$ valuation according to the real options approach, this article can be contrasted with Herath and Park (1999, 2001, 2002). Herath and Park (1999) applied the option-based valuation approach to show that sequential exercising of real options can create stockholder value. In particular, by applying their model to Gillette's Mach3 project they demonstrated that more meaningful interpretations are possible by using the option approach rather 
than the traditional Discounted Cash Flow (DCF) method to value R\&D projects. Herath and Park (2001), recognizing the important role played by information on real options value as business conditions change over time, intersected the real options approach and Bayesian analysis. Therefore, combining old and new information sequentially over time, it is possible to capture the real options value changes over time as a result of uncertainty resolution. Herath and Park (2002) developed a compound real options valuation model contingent on several uncorrelated underlying variables and, after estimating the volatility parameter, applied it to a manufacturing case. Finally, the analysis of investment decisions within the real options approach in a game theoretical setting has been the subject of intense research interest. Recent surveys of real options and strategic competition may be found in Boyer et al. (2004), Cortelezzi and Marseguerra (2006), Pennings and Sereno (2011), Cassimon (2011), and Zandi and Tavana (2010) and applications of strategic competition can be found, for example in Cortelezzi and Villani (2008), Cortelezzi et al. (2011) and Marseguerra and Cortelezzi (2010).

In this article, we enrich our understanding of strategic investment decisions in $R \& D$, including a key characteristic of $R \& D$ processes; that is, information revelation. $R \& D$ investment decisions are often difficult to reverse, and the timing of investment in an R\&D project is a crucial strategic decision for a firm. Early investment can be expensive, but could yield a significant competitive advantage. A late investment can benefit from the information revealed by the competitor. We consider the irreversible investment decisions of a couple of firms that must decide whether and when to invest in an R\&D project. Firms face different kinds of uncertainty. First, there is exogenous uncertainty about investment and development costs and final market conditions. Second, there is uncertainty about the success of the R\&D project. Of these two assumptions, the former is distinctive of the literature on real options approaches to investments, whereas the latter characterizes the R\&D investment project. Both firms have time flexibility; that is, they have the opportunity either to make the investment or wait for one period and collect new information on the evolution of the project and the final market conditions. In accordance, we model the compound R\&D options as American exchange options and derive the strategies and equilibria of the game played by the two firms considered.

This article is organized as follows: the following section describes the basic assumption of the model. The next two sections are devoted to derive the leader's and the follower's value functions respectively in the case of sequential and simultaneous investment. Then the results of numerical simulations are presented and some comparative static analyses are performed. The final section concludes the article.

\section{The Model}

Let us consider two symmetric and risk-neutral firms, $i, j \in(A, B)$, engaged in a two-stage competition over a finite horizon $T$. Both firms hold a compound option to invest in an R\&D project. Specifically, both firms have the opportunity to make an R\&D investment by incurring a research investment cost $R$. If the investment is successful, they obtain the option to develop the project at the development $\operatorname{cost} \gamma D$, whose returns, $\gamma V$, are uncertain, where $\gamma=\alpha>\frac{1}{2}$ is the market share if the firm considered is the market leader $(\gamma=1-\alpha$ is the market share if it is the follower). By setting the R\&D investment early on, a firm may preempt the competitor and capture a significant share of the market, $\alpha>\frac{1}{2}$. This is an important source of advantage that may establish a sustainable strategic position. At the same time, the firm that postpones investment can capture information about its $R \& D$ 
success by observing the R\&D performance of the other. Thus, development costs and returns are proportional to the market share of the firm considered. We assume that $D$ and $V$ follow a geometric Brownian motion process, respectively given, by:

$$
\begin{aligned}
\frac{d D}{D} & =\left(\mu_{d}-\delta_{d}\right) d t+\sigma_{d} d Z_{d} \\
\frac{d V}{V} & =\left(\mu_{v}-\delta_{v}\right) d t+\sigma_{v} d Z_{v} \\
\operatorname{cov}\left(\frac{d V}{V}, \frac{d D}{D}\right) & =\rho_{v d} \sigma_{v} \sigma_{d} d t
\end{aligned}
$$

where $\mu_{d}$ and $\mu_{v}$ are, respectively, the expected growth rate of the development cost and the expected rate of return, $\delta_{d}$ and $\delta_{v}$ are the corresponding dividend yields, $\sigma_{d}$ and $\sigma_{v}$ are the respective variance rates, $\rho_{v d}$ is the correlation between changes in $D$ and $V$, and $\left(Z_{d t}\right)_{t \in[0, T]}$ and $\left(Z_{v t}\right)_{t \in[0, T]}$ are two Brownian processes defined on a filtered probability space $(\Omega, A, F, P)$.

We further assume that $R$ is a proportion of $D, R=\varphi D, \varphi \in(0,1)$. As a consequence, $R$ follows the same stochastic process. The main difference is that $R$ can be spent either at the initial time $t_{0}$ or one period later, at $t_{1}$, whereas the option $\gamma D$ can be exercised at any time before $T$.

The main feature of our model is represented by the assumption relative to the information revelation. In fact, the precise payoff upon exercise is not fully known to any of the firms. In particular, once a firm has realized the research investment, $R$, it holds an independent signal on the true realized payoff from investment; that is, it verifies the probability of success of the investment. Therefore, each agent's optimal exercise strategy will be contingent not only on his own signal but also on the observed action of the other agent. As a consequence, we assume that the probabilities of success of each firm, which we denote by $Y$ for firm A and by $X$ for firm B, are modeled according to two different Bernoulli distributions:

$$
Y:\left\{\begin{array}{cc}
1 & q \\
0 & 1-q
\end{array} \quad X:\left\{\begin{array}{cc}
1 & p \\
0 & 1-p
\end{array}\right.\right.
$$

where $q \in[0,1]$ and $p \in[0,1]$, and they mainly depend on the know-how of each player. Moreover, the R\&D success or failure of one firm generates an information revelation that influences the investment decision of the other firm. Specifically, if the R\&D investment of firm A is successful, firm B's probability $p$ changes to positive information revelation $p^{+}$, where $p$ changes to negative information revelation $p^{-}$in the case of A's failure. Symmetrically, firm A's R\&D success changes to $q^{+}$or in $q^{-}$respectively, in case of firm B's success or failure at time $t_{0}$. In particular (see Dias [2004] for details),

$$
\begin{aligned}
& p^{+}=\operatorname{Prob}[X=1 / Y=1]=p+\sqrt{\frac{1-q}{q}} \cdot \sqrt{p(1-p)} \cdot \rho(X, Y) \\
& p^{-}=\operatorname{Prob}[X=1 / Y=0]=p-\sqrt{\frac{q}{1-q}} \cdot \sqrt{p(1-p)} \cdot \rho(X, Y)
\end{aligned}
$$




$$
\begin{aligned}
& q^{+}=\operatorname{Prob}[Y=1 / X=1]=q+\sqrt{\frac{1-p}{p}} \cdot \sqrt{q(1-q)} \cdot \rho(X, Y) \\
& q^{-}=\operatorname{Prob}[Y=1 / X=0]=q-\sqrt{\frac{p}{1-p}} \cdot \sqrt{q(1-q)} \cdot \rho(X, Y)
\end{aligned}
$$

where the correlation coefficient, $\rho(X, Y)$, is a measure of information revelation from one player to the other. Obviously, the information revelation is considerable when the investment is not realized at the same time. On the contrary, if both players invest simultaneously in $R \& D$ or, alternatively, both of them decide to wait to invest, there is no information revelation $[\rho(X, Y)=0]$ and, consequently, we have the unconditional success probabilities $p=p^{+}=p^{-}$and $q=q^{+}=q^{-}$. In what follows, we are interested in evaluating the opportunity of this R\&D investment project at date $s \leq t_{0}$, when two different firms are competing in the final product market in presence of information revelation. We first derive the final payoff of being a follower and a leader, in the case of both a sequential and simultaneous investment. We then derive the optimal strategy of the game described. We solve the timing game by evaluating the compound option as an American exchange option. Although it is not possible to obtain a closed-form solution, we develop Monte Carlo simulations that allow us to value the project and determine the optimal strategy adopted efficiently by each firm.

\section{The Leader's and the Follower's Value Functions: The Sequential Investment Case}

In this section, we first derive the follower's value function, with the additional information revealed by the leader research investment. The follower will revise the expectations on his probability of success, determining whether the option to invest is deep in the money or not. The follower is therefore a pure real options case because there is no strategic interaction after the first exercise. We then compute the leader's value function. The leader has to decide whether and when to invest in research and obtain the development option with some probability, given by his Bernoulli distribution.

\section{The Follower's Payoff}

Let us first consider the case in which the leader (firm A) has already invested at $t_{0}$ and the follower (firm B) decides to delay its R\&D investment decision until time $t_{1}$ (we assume firm A to be the leader and firm B to be the follower. Note that the game is perfectly symmetric; therefore, the same analysis can be replicated assuming firm B to be the leader and firm A to be the follower. At the end of this section, we report the result of this last case.) Two cases must be considered: (1) the leader's R\&D investment is successful; (2) the leader's R\&D investment is a failure.

Let us first analyze the case in which the leader's investment is successful. In this case the follower's R\&D success probability is $p^{+}$. Therefore, once the follower sustains the investment cost $R$, he gets the development option $S[(1-\alpha) V,(1-\alpha) D, \tau)]$ to invest $(1-\alpha) D$ at any time $t \in\left(t_{1}, T\right)$ (we remember that the follower claims the residual market share $1-\alpha$ of the overall market value $V$ ). It is worth noting that the investment cost in $\mathrm{R} \& \mathrm{D}$ will be sustained if and only if $p^{+} S[(1-\alpha) V,(1-\alpha) D, \tau] \geq R$; that is, if the value of the development option is greater than the investment cost. The follower's payoff at time $t_{0}$ is therefore a compound American exchange option (CAEO) with maturity 


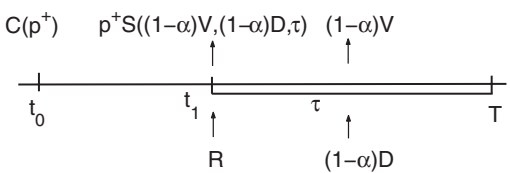

(a) Follower's Payoff in case of Leader's success

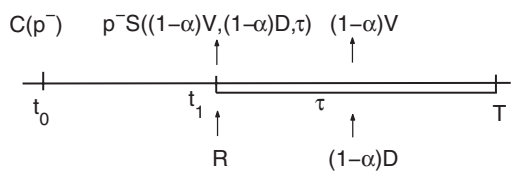

(b) Follower's Payoff in case of Leader's failure

Figure 1. Follower's payoffs.

at $t_{1}$, the exercise price equal to $R$, and the underlying asset is the development option $S[(1-\alpha) V,(1-\alpha) D, \tau]$. Figure 1a summarizes the timing of the game.

The CAEO payoff at the expiration date $t_{1}$ with positive information revelation is given by:

$$
C\left\{p^{+} S[(1-\alpha) V,[1-\alpha) D, \tau], R, 0\right\}=\max \left\{p^{+} S[(1-\alpha) V,(1-\alpha) D, \tau]-R, 0\right\}
$$

Since $R=\varphi D$, denoting by $C\left(p^{+}\right)$the CAEO at time $t_{0}$, we get:

$$
C\left(p^{+}\right) \equiv C\left\{p^{+} s[(1-\alpha) V,(1-\alpha) D, \tau], \varphi D, t_{1}\right\}
$$

By using Eq. (B5) it is possible to approximate the value of CAEO with positive information as follows (see Appendix B for a detailed derivation):

$$
\begin{aligned}
& C\left(p^{+}\right) \\
& \simeq \frac{\left.4 c_{2}\left\{p^{+} S_{2}[(1-\alpha) V,(1-\alpha) D, \tau], \varphi D, t_{1}\right\}-c\left\{p^{+} s[(1-\alpha) V,(1-\alpha) D, \tau], \varphi D, t_{1}\right)\right\}}{3}
\end{aligned}
$$

Alternatively, in case of the leader's investment failure, the follower's success probability become $p^{-}$. As above, he holds the development option $S[(1-\alpha) V,(1-\alpha) D, \tau]$ to invest $(1-\alpha) D$ at any time $t \in\left(t_{1}, T\right)$ and to claim the market value $(1-\alpha) V$. The follower's payoff at time $t_{0}$ is a CAEO with maturity $t_{1}$, the exercise price equal to $R$, and the underlying asset is equal to the development option $S[(1-\alpha) V,(1-\alpha) D, \tau]$ as shown in Figure 1b. Hence, the CAEO payoff with negative information revelation at the expiration date $t_{1}$ is given by:

$$
C\left\{p^{-} S[(1-\alpha) V,(1-\alpha) D, \tau], R, 0\right\}=\max \left\{p^{-} S[(1-\alpha) V,(1-\alpha) D, \tau]-R, 0\right\}
$$

Denoting by $C\left(p^{-}\right)$the CAEO at time $t_{0}$, we get:

$$
C\left(p^{-}\right) \equiv C\left\{p^{-} S[(1-\alpha) V,[1-\alpha) D, \tau], \varphi D, t_{1}\right\}
$$

As in the previous case, by using Eq. (B5), the value of CAEO with negative information is as follow:

$$
\begin{aligned}
& C\left(p^{-}\right) \\
& \quad \simeq \frac{4 c_{2}\left\{p^{-} S_{2}[(1-\alpha) V,(1-\alpha) D, \tau], \varphi D, t_{1}\right\}-c\left\{p^{-} s[(1-\alpha) V,(1-\alpha) D, \tau], \varphi D, t_{1}\right\}}{3}
\end{aligned}
$$

It is worth noting that the follower obtains the CAEO $C\left(p^{+}\right)$in the case of the leader's success with a probability $q$ or the CAEO $C\left(p^{-}\right)$in the case of the leader's failure with a 


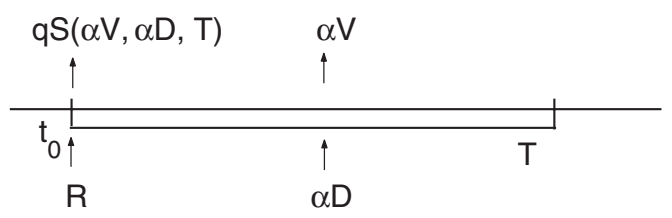

Figure 2. Leader's payoff.

probability $(1-q)$. Hence, the follower's final payoff computed at time $t_{0}, F_{B}(V, D)$, is just the expected value of this two cases; that is:

$$
F_{B}(V, D)=q C\left(p^{+}\right)+(1-q) C\left(p^{-}\right)
$$

Since the game is symmetric - that is, none of the firms is either a predesignated leader or follower-one should also consider the case that firm B is the leader. In this case the follower's final payoff at time $t_{0}, F_{A}(V, D)$,

$$
F_{A}(V, D)=p C\left(q^{+}\right)+(1-p) C\left(q^{-}\right)
$$

\section{The Leader's Payoff}

We now analyze the case in which the leader (firm A) invests in the R\&D project at time $t_{0}$, whereas the follower (firm B) decides to postpone its decision, waiting for information revelation. In such a scenario, the leader sustains the investment research cost $R$ at time $t_{0}$ and obtains, in the case of success with a probability $q$, the development option $S(\alpha V, \alpha D, T)$ that gives the opportunity to invest $\alpha D$ at any time $t \in\left(t_{0}, T\right)$ and to get a market share $\alpha>\frac{1}{2}$, as illustrated in Figure 2. Thus, the leader's payoff is (for a detailed derivation see Armada et al. [2007]):

$$
\begin{aligned}
L_{A}(V, D) & =-R+q \cdot S(\alpha V, \alpha D, T) \\
& \simeq-R+q\left[\frac{4 S_{2}(\alpha V, \alpha D, T)-s(\alpha V, \alpha D, T)}{3}\right]
\end{aligned}
$$

Since the game is symmetric and none of the firms is a predesignated leader, one should also consider the case in which firm B is the leader. In this case the leader's final payoff at time $t_{0}$ is as follow:

$$
\begin{aligned}
L_{B}(V, D) & =-R+p \cdot S(\alpha V, \alpha D, T) \\
& \simeq-R+p\left[\frac{4 S_{2}(\alpha V, \alpha D, T)-s(\alpha V, \alpha D, T)}{3}\right]
\end{aligned}
$$

\section{The Leader's and the Follower's Value Functions: \\ The Simultaneous Investment Case}

Let us now consider the case in which both the leader and the follower invest at the same time, either at $t=t_{0}$ or at $t=t_{1}$. In such a situation there are no information externalities $[\rho(X, Y)=0]$ that can be used to revise the expectation about the profitability of the 


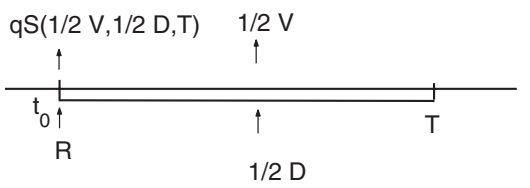

(a) Firm A's payoff

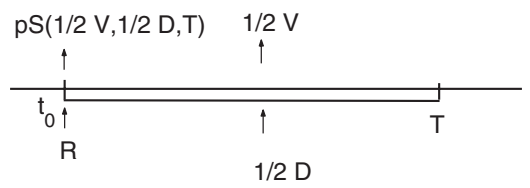

(b) Firm B's payoff

Figure 3. A's and B's payoff in case of simultaneous investment.

investment. Since the investment is simultaneous, we assume that firms share the overall market value; that is, $\alpha=\frac{1}{2}$. Two cases must be considered: (1) both firms invest at $t=t_{0}$; (2) both firms invest at $t=t_{1}$.

Let us first assume that both firms invest at $t=t_{0}$; that is, both firms $\mathrm{A}$ and $\mathrm{B}$ decide separately to incur the sunk cost $R$ in the R\&D project. They have respectively some probability $q$ and $p$ to hold the development option $S\left(\frac{1}{2} V, \frac{1}{2} D, T\right)$ and invest $\frac{1}{2} D$ at any time $t \in\left(t_{0}, T\right)$, as illustrated in Figures $3 \mathrm{a}$ and $3 \mathrm{~b}$.

Thus, by using Eq. (B3), the payoffs for firm A, $S_{A}(V, D)$, and B, $S_{B}(V, D)$, are respectively the following (see Appendix $\mathrm{B}$ for a detailed derivation):

$$
\begin{aligned}
S_{A}(V, D) & =-R+q \cdot S\left(\frac{1}{2} V, \frac{1}{2} D, T\right) \\
& \simeq-R+q\left[\frac{4 S_{2}\left(\frac{1}{2} V, \frac{1}{2} D, T\right)-s\left(\frac{1}{2} V, \frac{1}{2} D, T\right)}{3}\right] \\
S_{B}(V, D) & =-R+p \cdot S\left(\frac{1}{2} V, \frac{1}{2} D, T\right) \\
& \simeq-R+p\left[\frac{4 S_{2}\left(\frac{1}{2} V, \frac{1}{2} D, T\right)-s\left(\frac{1}{2} V, \frac{1}{2} D, T\right)}{3}\right]
\end{aligned}
$$

Let us now assume that both firms invest at $t=t_{1}$; that is, both firms $\mathrm{A}$ and $\mathrm{B}$ decide separately to incur the sunk cost $R$ in the R\&D project one period later. As before, in the case of success, each firm holds the development option $S\left(\frac{1}{2} V, \frac{1}{2} D, \tau\right)$ to invest $\frac{1}{2} D$ at any time $t \in\left(t_{1}, T\right)$ and claims a market share $\frac{1}{2} V$. Therefore, at time $t_{0}$, the firms' payoffs are two compound American exchange options with maturity $t_{1}$, the exercise price equal to $R=\varphi D$, and the underlying asset is the development option $S\left(\frac{1}{2} V, \frac{1}{2} D, T\right)$ with probabilities $q$ and $p$, respectively, as illustrated in Figures $4 \mathrm{a}$ and $4 \mathrm{~b}$.

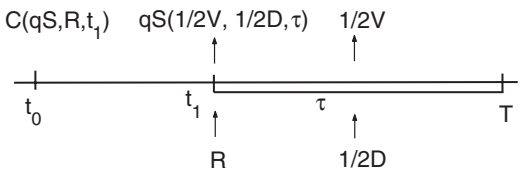

(a) Firm A's payoff

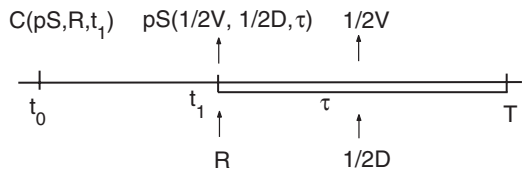

(b) Firm B's payoff

Figure 4. A's and B's payoffs in the case of waiting to invest. 


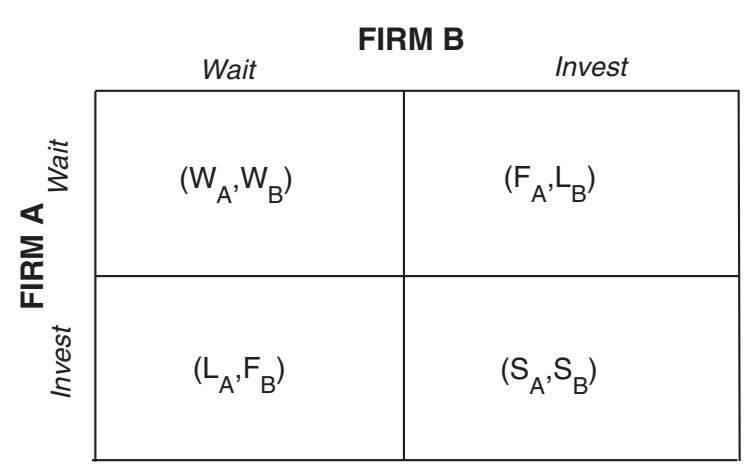

Figure 5. Final payoffs at time $t_{0}$.

Thus, A's and B's payoff, $W_{A}(V, D)$ and $W_{B}(V, D)$, at time $t_{0}$ is given by:

$$
\begin{aligned}
& W_{A}(V, D)=C\left[q \cdot S\left(\frac{1}{2} V, \frac{1}{2} D, \tau\right), \varphi D, t_{1}\right] \\
& W_{B}(V, D)=C\left[p \cdot S\left(\frac{1}{2} V, \frac{1}{2} D, \tau\right), \varphi D, t_{1}\right]
\end{aligned}
$$

As above, by using Eq. (B5), it is possible to approximate firm A's and B's waiting payoffs as follows:

$$
\begin{aligned}
W_{A}(V, D) & \simeq \frac{4 c_{2}\left[q S_{2}\left(\frac{1}{2} V, \frac{1}{2} D, \tau\right), \varphi D, t_{1}\right]-c\left[q S\left(\frac{1}{2} V, \frac{1}{2} D, \tau\right), \varphi D, t_{1}\right]}{3} \\
W_{B}(V, D) & \simeq \frac{4 c_{2}\left[p S_{2}\left(\frac{1}{2} V, \frac{1}{2} D, \tau\right), \varphi D, t_{1}\right]-c\left(p S\left[\frac{1}{2} V, \frac{1}{2} D, \tau\right), \varphi D, t_{1}\right]}{3}
\end{aligned}
$$

\section{The Firms' Payoffs Matrix}

The final payoffs can be represented by a two-by-two matrix (see Figure 5). The first value in each cell indicates the final payoff for firm $\mathrm{A}$ at time $t_{0}$ and the second value represents the final payoff for firm B. We can distinguish four basic cases: (i) both firms decide to postpone the R\&D investment at time $t_{1}$; (ii) and (iii) one firm invests first (the leader) and the other decides to invest one period later (the follower); (iv) both firms decide to invest simultaneously in R\&D at time $t_{0}$.

\section{Analysis of the Model}

We now examine the characteristics of the optimal investment strategies through the determination of the Nash equilibria of the game and show how they depend on the value of some fundamental parameters. This model can be applied to analyze the R\&D investments in several industrial sectors such as high-tech, pharmaceutical, telecommunication, or oil extraction, in which competitors can substantially influence a firm's investment opportunity. Because it is not possible to obtain a closed-form solution, we perform some numerical simulations using a Monte Carlo method. 
We established a set of central values for the parameters based on Lee and Paxson (2001) and Dias and Teixeira (2004).

Let us consider a firm that faces the possibility of sustaining a research investment cost $R$ either at time $t_{0}$ or $t_{1}$. If the investment is made at $t_{0}$, we set the research investment cost, $R$, equal to $\$ 150,000$; otherwise, it occurs at $t_{1}$ and it is a proportion, $\varphi$, equal to 0.375 , of the total development cost, $D$. As a consequence, at time $t_{1}$, the research investment cost $R$ follows the same stochastic process of $D$. We set the total investment cost, $D$, equal to $\$ 400,000$.

We assume that the first firm to invest, namely, firm A in our simulated example, has greater and more efficient know-how than her competitor, firm B. Thus, firm A's success probability is $q$ equal to 0.60 , whereas firm B's success probability is $p$ equal to 0.55 .

As is standard in real options models, we assume that the volatility of quoted shares and traded options is an adequate proxy for the volatility of the final market value $V$ and the development investment cost $D$. Moreover, the R\&D investments usually present greater uncertainty in their results. Thus, we set the volatility of the project value, $\sigma_{v}$, equal to $0.90 \%$ annually and the volatility of the development option, $\sigma_{d}$, equal to $0.23 \%$ annually. The loss of cash flow during the life of the option by deferring the project, $\delta_{v}$, is established equal to $0.15 \%$ annually and the dividend yield on the development cost, $\delta_{d}$, has been set equal to 0 .

The time to maturity, $T$ - that is, the project's deferment option after which each opportunity disappears - has been set equal to 3 years. Moreover, because the follower needs at least 6 months to know the leader's outcome and, consequently, to receive the information revelation, we set $t_{1}$ equal to 0.5 years.

Table 1 summarizes the set of base-case parameter values for our numerical simulation results.

We first observe that, when the expected market value $V$ is equal to 0 , the simple and compound American exchange option values are zero and so $L_{i}(0)=S_{i}(0)=-R$ and $F_{i}(0)=W_{i}(0)=0$, for $i=A, B$. We present in Table 2 the results of the Monte Carlo simulations for the follower's and waiting payoffs, given the base-case parameters described above. We consider five different expected overall market values, $V$, according to the

Table 1

Base case parameter values

\begin{tabular}{ll}
\hline Parameter & Value \\
\hline R\&D investment & $R=\$ 150,000$ \\
Development investment & $D=\$ 400,000$ \\
Costs volatility & $\sigma_{d}=0.23 \%$ annually \\
Market volatility & $\sigma_{v}=0.90 \%$ annually \\
Proportion of $D$ required for $R$ & $\varphi=\frac{R}{D}=0.375$ \\
Convenience yield of $D$ & $\delta_{d}=0$ \\
Convenience yield of $V$ & $\delta_{v}=0.15 \%$ annually \\
Correlation between $V$ and $D$ & $\rho_{v d}=0.15$ \\
Expiration date of compound option & $t_{1}=0.5$ years \\
Expiration date of simple option & $T=3$ years \\
A's and B's success probability & $q=0.60 ; p=0.55$ \\
Information revelation & $\rho(X, Y)=0.70$ \\
Leader's market share & $\alpha=0.60$ \\
\hline
\end{tabular}


Table 2

Simulated values of follower and waiting strategies

\begin{tabular}{lcccrr}
\hline Strategy & $\begin{array}{c}\text { 1st } \\
\text { Monte Carlo }\end{array}$ & $\begin{array}{c}\text { 2nd } \\
\text { Monte Carlo }\end{array}$ & $\begin{array}{c}\text { 3rd } \\
\text { Monte Carlo }\end{array}$ & $\begin{array}{c}\text { 4th } \\
\text { Monte Carlo }\end{array}$ & $\begin{array}{c}\text { Average } \\
\text { value }\end{array}$ \\
\hline$F_{A}(800,000)$ & 26,620 & 26,525 & 26,573 & 26,663 & 26,595 \\
$F_{B}(800,000)$ & 23,936 & 23,862 & 23,916 & 23,999 & 23,928 \\
$W_{A}(800,000)$ & 30,760 & 30,675 & 30,777 & 30,875 & 30,772 \\
$W_{B}(800,000)$ & 25,191 & 25,133 & 25,227 & 25,323 & 25,219 \\
$F_{A}(1,000,000)$ & 47,146 & 47,147 & 47,103 & 47,087 & 47,120 \\
$F_{B}(1,000,000)$ & 43,232 & 43,060 & 43,024 & 42,988 & 43,076 \\
$W_{A}(1,000,000)$ & 56,355 & 56,123 & 56,089 & 56,004 & 56,143 \\
$W_{B}(1,000,000)$ & 47,146 & 46,925 & 46,900 & 46,780 & 46,938 \\
$F_{A}(1,200,000)$ & 72,288 & 72,286 & 71,908 & 72,176 & 72,164 \\
$F_{B}(1,200,000)$ & 66,707 & 66,711 & 66,359 & 66,608 & 66,596 \\
$W_{A}(1,200,000)$ & 87,566 & 87,618 & 87,150 & 87,484 & 87,455 \\
$W_{B}(1,200,000)$ & 74,349 & 74,369 & 73,977 & 74,261 & 74,239 \\
$F_{A}(1,400,000)$ & 100,510 & 100,750 & 100,510 & 100,420 & 100,548 \\
$F_{B}(1,400,000)$ & 93,460 & 93,687 & 93,460 & 93,356 & 93,491 \\
$W_{A}(1,400,000)$ & 123,240 & 123,530 & 123,240 & 123,030 & 123,260 \\
$W_{B}(1,400,000)$ & 105,810 & 106,060 & 105,810 & 105,650 & 105,833 \\
$F_{A}(1,600,000)$ & 130,940 & 131,290 & 131,430 & 131,440 & 131,275 \\
$F_{B}(1,600,000)$ & 122,380 & 122,720 & 122,830 & 122,870 & 122,700 \\
$W_{A}(1,600,000)$ & 161,490 & 162,000 & 162,020 & 162,130 & 161,910 \\
$W_{B}(1,600,000)$ & 139,850 & 140,290 & 140,330 & 140,460 & 140,233 \\
\hline
\end{tabular}

evolution of the market conditions: $V=\$ 800,000$ (low expected return); $V=\$ 1,000,000$, $V=\$ 1,200,000$ (medium expected return), and $V=\$ 1,400,000$ and $V=\$ 1,600,000$ (high expected return). Note that $V$ corresponds to the present value of the expected cash flows derived by $R \& D$ innovations. For each scenario, we perform four different simulations and, specifically, for each simulation, the number of simulated values $n$ is equal to 100,000 . As shown in Cortelezzi and Villani (2009), this simulation number allows us to obtain a low variance and to improve the efficiency of computations.

Tables 3 and 4 summarize the strategic payoffs for A and B considering different expected market values, and Figures 6 and 7 show firm A's and from B's strategic values.

Table 3

Firm A's final payoffs assuming $\alpha=0.60$ and $\rho(X, Y)=0.70$

\begin{tabular}{rrrrr}
\hline $\begin{array}{l}\text { Market } \\
\text { value } V\end{array}$ & $\begin{array}{c}\text { Leader's } \\
\text { value } L_{A}\end{array}$ & $\begin{array}{c}\text { Follower's } \\
\text { value } F_{A}\end{array}$ & $\begin{array}{c}\text { Simultaneous } \\
\text { value } S_{A}\end{array}$ & $\begin{array}{c}\text { Waiting } \\
\text { value } W_{A}\end{array}$ \\
\hline 800,000 & $-4,474$ & 26,595 & $-28,728$ & 30,772 \\
$1,000,000$ & 48,152 & 47,120 & 15,126 & 56,143 \\
$1,200,000$ & 102,894 & 72,164 & 60,745 & 87,455 \\
$1,400,000$ & 159,113 & 100,548 & 107,594 & 123,260 \\
$1,600,000$ & 216,402 & 131,275 & 155,335 & 161,910 \\
\hline
\end{tabular}


Table 4

Firm B's final payoffs assuming $\alpha=0.60$ and $\rho(X, Y)=0.70$

\begin{tabular}{rrrrr}
\hline $\begin{array}{l}\text { Market } \\
\text { value } V\end{array}$ & $\begin{array}{r}\text { Leader's } \\
\text { value } L_{B}\end{array}$ & $\begin{array}{c}\text { Follower's } \\
\text { value } F_{B}\end{array}$ & $\begin{array}{c}\text { Simultaneous } \\
\text { value } S_{B}\end{array}$ & $\begin{array}{c}\text { Waiting } \\
\text { value } W_{B}\end{array}$ \\
\hline 800,000 & $-16,601$ & 23,928 & $-38,834$ & 25,219 \\
$1,000,000$ & 31,639 & 43,076 & 1,366 & 46,938 \\
$1,200,000$ & 81,819 & 66,596 & 43,183 & 74,239 \\
$1,400,000$ & 133,354 & 93,491 & 86,128 & 105,833 \\
$1,600,000$ & 185,869 & 122,700 & 129,891 & 140,233 \\
\hline
\end{tabular}

In order to determine the Nash equilibria of the game, we first perform Monte Carlo simulations to compute the critical market values $V_{W i}^{*}$ and $V_{S i}^{*}$ such that, respectively, $L_{i}\left(V_{W i}^{*}\right)=W_{i}\left(V_{W i}^{*}\right)$ and $S_{i}\left(V_{S i}^{*}\right)=F_{i}\left(V_{S i}^{*}\right)$, for $i=A, B$. We obtain the following values:

$$
V_{W A}^{*} \simeq \$ 1,070,000 ; \quad V_{W B}^{*} \simeq \$ 1,130,000 ; \quad V_{S A}^{*} \simeq \$ 1,320,000 ; \quad V_{S B}^{*} \simeq \$ 1,490,000 .
$$

Moreover, the critical price value, $P_{2}^{*}$, that realizes the indifference between exercising the option or not at $\frac{\tau}{2}$ of a Pseudo-simple American Exchange Option (PSAEO) $S_{2}\left(V, D, \frac{\tau}{2}\right)$, is the solution of Eq. (A13) illustrated in Appendix A. For our adapted numbers it results in $P_{2}^{*}=1.6722$.

Thus, defining $V_{W}^{*}=\min \left(V_{W A}^{*}, V_{W B}^{*}\right), V_{Q}^{*}=\max \left(V_{W A}^{*}, V_{W B}^{*}\right), V_{P}^{*}=\min \left(V_{S A}^{*}, V_{S B}^{*}\right)$, and $V_{S}^{*}=\max \left(V_{S A}^{*}, V_{S B}^{*}\right)$, the following relations hold:

$$
\begin{array}{ll}
L_{i}(V)<W_{i}(V) & \text { if } V<V_{W}^{*} \\
L_{i}(V)>W_{i}(V) & \text { if } V>V_{Q}^{*}
\end{array}
$$
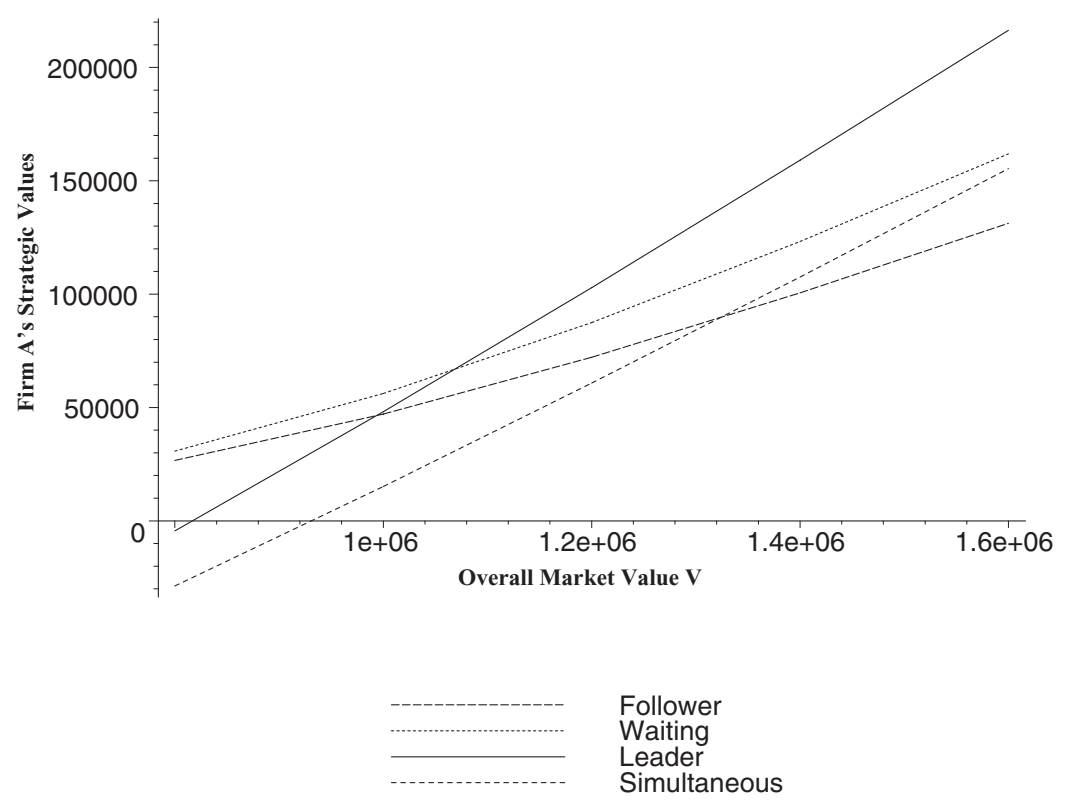

Figure 6. Firms A's strategic values. 

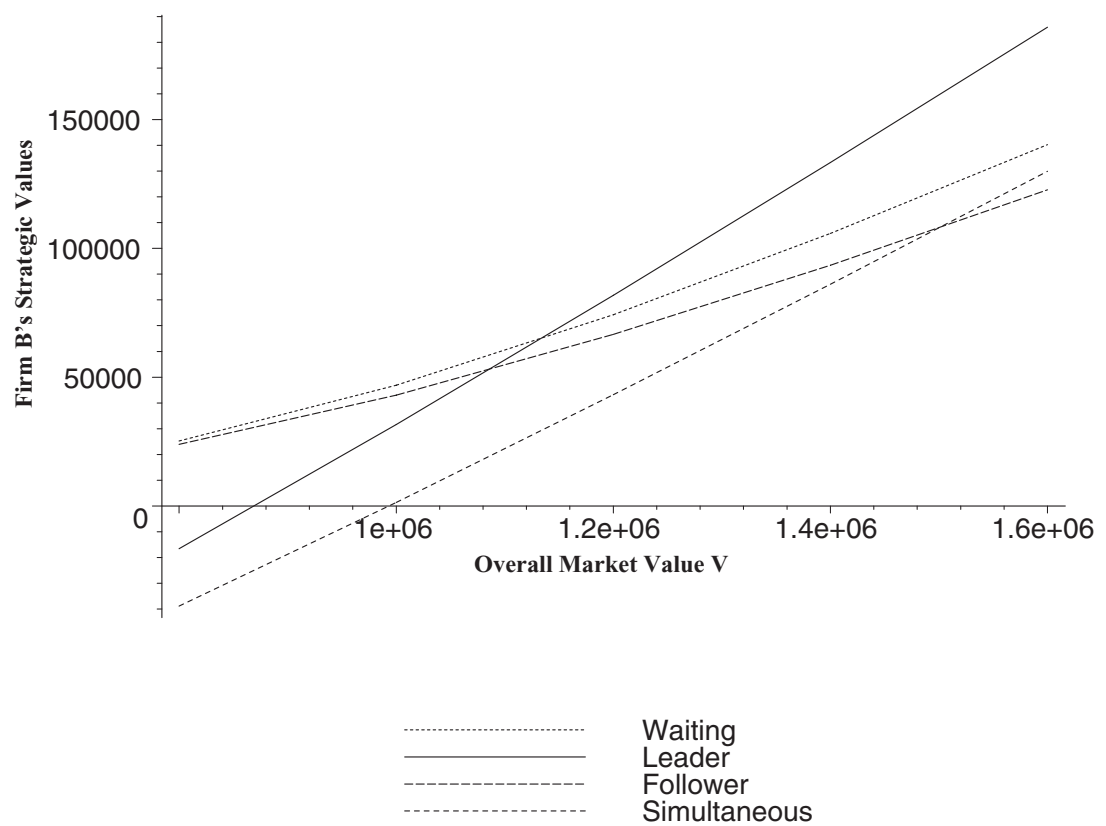

Figure 7. Firms B's strategic values.

$$
\begin{array}{ll}
S_{i}(V)<F_{i}(V) & \text { if } V<V_{P}^{*} \\
S_{i}(V)>F_{i}(V) & \text { if } V>V_{S}^{*}
\end{array}
$$

Moreover, if A's probability of success is higher (lower) than B's

$$
\begin{gathered}
L_{A}(V)>(<) W_{A}(V) \\
L_{B}(V)<(>) W_{B}(V) \\
S_{A}(V)>(<) F_{A}(V) \\
S_{B}(V)<(>) F_{B}(V)
\end{gathered}
$$

Let us first assume that the expected market value, $V$, is equal to $\$ 800,000$ (low return). In such a scenario, we find a Nash equilibrium in which both firms prefer to wait for better market evolutions and delay their R\&D investment decision at time $t_{1}$ (see Figure 8a).

Let us now assume that the expected market value $V$ is equal to $\$ 1,600,000$ (high return). In this case there is a Nash equilibrium $\left(S_{A}, S_{B}\right)$ in which both firms decide to invest simultaneously in R\&D at time $t_{0}$ to take advantage of high market value (see Figure $8 \mathrm{~d}$ ). Assuming now $V=\$ 1,400,000$, there exists one Nash equilibrium $\left(L_{A}, F_{B}\right)$ in which firm $\mathrm{A}$ is the leader and firm B is the follower (see Figure 8c).

Finally, by assuming $V=\$ 1,200,000$, we find two Nash equilibria, $\left(L_{A}, F_{B}\right)$ and $\left(F_{A}, L_{B}\right)$, as represented in Figure $8 \mathrm{~b}$. In the first equilibrium firm A invests immediately 


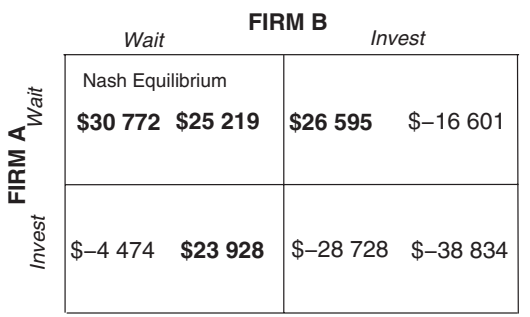

(a) I Case: $V=\$ 800000$

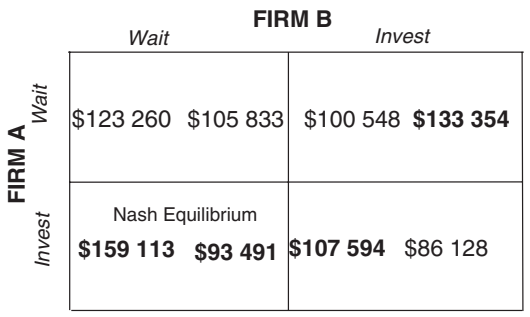

(c) III Case: $V=\$ 1400000$

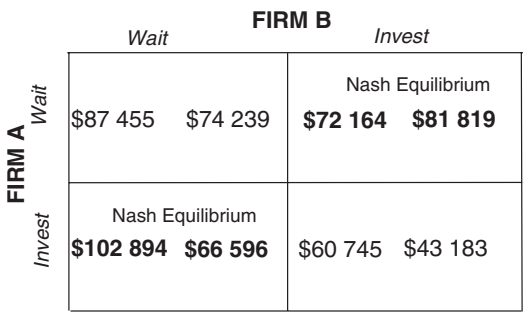

(b) II Case: $V=\$ 1200000$

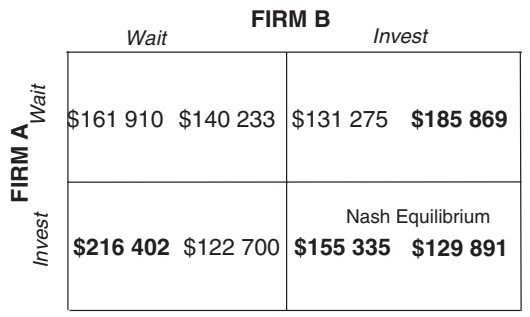

(d) IV Case: $V=\$ 1600000$

Figure 8. Final payoffs.

at time $t_{0}$ and $\mathrm{B}$ postpones its $\mathrm{R} \& \mathrm{D}$ decision at time $t_{1}$ for waiting better information; the opposite holds in the second equilibrium.

It is worth noting that for the extreme value of the expected market value $V$, see Figures $8 \mathrm{a}$ and $8 \mathrm{~d}$, there are equilibria in dominant strategies. Moving from these extreme values, the dominant strategy survives only for one of the two firms (Figure 8c). This ensure the existence of a unique Nash equilibrium. However, there are intermediate values of $V$ for which none of the firms have dominant strategies. In this case, multiple equilibria are possible (Figure 8b) and a refinement of the equilibria is necessary.

\section{Comparative Static Results}

We are now interested in analyzing the, effects that the information revelation, $\rho(X, Y)$; the first mover's advantage, $\alpha$; and the dividend yield, $\delta_{v}$, have on the Nash equilibria derived above.

First, comparing strategic payoffs computed using American options versus European ones, it is immediately observed that the first are larger then the second. This result is essentially due to the value of managerial flexibility to realize the investment $D$ prior to maturity $T$. In particular, it is worth noting that the critical market values $V_{W A}^{*}$ and $V_{S B}^{*}$ achieved using American exchange options decrease rapidly with respect to those obtained by European options. Denoting by $V_{W A}^{* E}$ and $V_{S B}^{* E}$ the critical market values obtained using McDonald and Siegel's (1985) and Carr's (1988) models of European option value (see, for details, Villani [2008]), we find that $V_{W A}^{* E}=\$ 1,349,400$ and $V_{S B}^{* E}=\$ 1,898,700$. Thus, the length of range game $\left[V_{W A}^{*}, V_{S B}^{*}\right]$ is equal to $[1,070,000,1,490,000]=\$ 420,000$, which is smaller than $[1,349,400,1,898,700]=\$ 549,300$ obtained using European options. This means that the managerial time flexibility regarding the realization of the development phase allows both firms to reduce the critical market values that bound both the opportunity to delay the R\&D investment decision (the so-called wait-and-see policy) and the simultaneous 
Table 5

Variation in information revelation with $\alpha=0,60$ and $\delta_{v}=0.15$

\begin{tabular}{lccccc}
\hline$\rho(X, Y)$ & $V_{S A}^{*}$ & $V_{S B}^{*}$ & $V_{W B}^{*}-V_{W A}^{*}$ & $V_{S A}^{*}-V_{W B}^{*}$ & $V_{S B}^{*}-V_{S A}^{*}$ \\
\hline 0 & $1,155,000$ & $1,228,000$ & 60,000 & 25,000 & 73,000 \\
0.10 & $1,165,000$ & $1,262,000$ & 60,000 & 35,000 & 97,000 \\
0.30 & $1,203,000$ & $1,307,000$ & 60,000 & 73,000 & 104,000 \\
0.50 & $1,235,000$ & $1,380,000$ & 60,000 & 105,000 & 145,000 \\
0.70 & $1,320,000$ & $1,490,000$ & 60,000 & 190,000 & 170,000 \\
0.90 & $1,439,000$ & $1,690,000$ & 60,000 & 309,000 & 251,000 \\
\hline
\end{tabular}

investment implementation. Evaluating the $R \& D$ investment problem according to the American exchange options methodology allows manager's to invest earlier. It is worth noting that in this case the R\&D investment can be realized at time $t_{0}$ with an initial value $V$ equal to $\$ 1,070,000$ instead of an initial value $V$ equal to $\$ 1,349,400$.

Table 5 shows the impact of information revelation on the ranges game. Moreover, the ranges game are the intervals in which arise particular equilibria. Note that in order to have $0 \leq p^{+} \leq 1$, and $0 \leq p^{-} \leq 1$, the following condition must be respected:

$$
0 \leq \rho(X, Y) \leq \min \left\{\sqrt{\frac{p(1-q)}{q(1-p)}}, \sqrt{\frac{q(1-p)}{p(1-q)}}\right\}
$$

In our applications, the result is $0 \leq \rho(X, Y) \leq 0.9026$. We can observe that the investing and waiting strategies are independent of $\rho(X, Y)$. Therefore, the critical market values $V_{W A}^{*}$ and $V_{W B}^{*}$ do not change and the range $\left[V_{W A}^{*}, V_{W B}^{*}\right]$ remains unchanged and equal to $\$ 60,000$. Moreover, as the information revelation increases, the payoff ranges $\left[V_{W B}^{*}, V_{S A}^{*}\right]$ that is, the area in which we find two Nash equilibria-and $\left[V_{S A}^{*}, V_{S B}^{*}\right]$; that is, where we find one Nash equilibrium, are enlarged.

Table 6 shows the impact of the first mover's advantage on the critical market values. We observe that, if the leader's market share $\alpha$ increases, then all of the critical market values decrease (in the limit case of $\alpha=1$; that is, the firm acts as a monopolist on the final market product, and the follower's strategy has no value). In particular, we can observe that as the market share, $\alpha$, increases, the ranges $\left[V_{W A}^{*}, V_{W B}^{*}\right]$ and $\left[V_{S A}^{*}, V_{S B}^{*}\right]$ are reduced, whereas $\left[V_{W B}^{*}, V_{S A}^{*}\right]$ increases; that is, the area in which it is possible to find two Nash equilibria increases.

Table 6

Variation in leader's market share with $\rho(X, Y)=0.70$ and $\delta_{v}=0.15$

\begin{tabular}{lrrrr}
\hline$\alpha$ & \multicolumn{1}{c}{$V_{W A}^{*}$} & \multicolumn{1}{c}{$V_{W B}^{*}$} & \multicolumn{1}{c}{$V_{S A}^{*}$} & \multicolumn{1}{c}{$V_{S B}^{*}$} \\
\hline 0.60 & $1,070,000$ & $1,130,000$ & $1,320,000$ & $1,490,000$ \\
0.70 & 858,000 & 906,000 & $1,070,000$ & $1,161,000$ \\
0.80 & 742,000 & 791,000 & 975,000 & $1,042,000$ \\
0.90 & 662,000 & 703,000 & 935,000 & 998,000 \\
1 & 609,000 & 645,000 & 932,000 & 993,000 \\
\hline
\end{tabular}


Finally, when the dividend yields $\delta_{d}$ and $\delta_{v}$ go to zero, then the CAEO and SAEO prices are equal to CEEO (see Carr [1988]) and SEEO (see McDonald and Siegel [1985]), respectively, because there is no incentive to exercise the American option prior to maturity date $T$. Thus, if $\delta_{v}$ is set equal to 0 , we find that $V_{W A}^{*} \simeq \$ 860,000$ and $V_{S B}^{*} \simeq \$ 1,305,000$.

\section{Concluding Remarks}

The $R \& D$ investment is one of the most important strategic variables for a successful firm performance. However, a R\&D investment opportunity is not held by one firm in isolation; therefore, competitive considerations are extremely important. In this article, we evaluate these kinds of projects according to the theory of option games, which bring together real options analysis and game theory. In particular, we apply the Monte Carlo simulations to value $\mathrm{R} \& \mathrm{D}$ as an American exchange option that take into account the managerial flexibility to realize the development investment $D$. We also consider the possibility of strategic interactions between the two firms. The first firm to invest, acquires a first mover advantage, and the second receives an information revelation from the leader's

$\mathrm{R} \& \mathrm{D}$ investment. We computed the critical market values $V_{W A}^{*}, V_{W B}^{*}, V_{S A}^{*}$, and $V_{S B}^{*}$, used to determine the range of parameters in which it is optimal to play each strategy, namely, to invest or to wait, and we show the effects that the most important parameters have on the game. We finally perform a comparative static analysis on the base case parameters and analyze how the equilibria of the game are modified.

\section{References}

Armada, M.R., Kryzanowsky, L. and Pereira, P.J. (2007) A modified finite-lived American exchange option methodology applied to real options valuation. Global Finance Journal, 17(3), 419-438.

Boyer, M., Gravel, E. and Lasserre, P. (2004) Real options and strategic competition: a survey. Working paper, University of Montreal.

Carr, P. (1988) The valuation of sequential exchange opportunities. The Journal of Finance, 43(5), $1235-1256$.

Carr, P. (1995) The valuation of American exchange options with application to real options. In Real options in capital investment: models, strategies and applications, edited by Lenos Trigeorgis. Praeger: Westport, CT.

Cassimon, D. (2011) Compound real option valuation with phase-specific volatility: a multi-phase mobile payments case study. Technovation, 31(5-6), 240-255.

Cortelezzi, F. and Marseguerra, G. (2006) Investimenti irreversibili, interazioni strategiche e opzioni reali: analisi teorica ed applicazioni. Economia Politica, 2, 265-302.

Cortelezzi, F. and Villani, G. (2008) Strategic technology adoption and market dynamics as option games. The Icfai Journal of Industrial Economics, 5(4), 7-27.

Cortelezzi, F. and Villani, G. (2009) Valuation of R\&D sequential exchange options using monte carlo approach. Computational Economics, 33(3), 209-236.

Cortelezzi, F., Giannoccolo, P. and Villani, G. (2011) Strategic urban development under uncertainty. The IUP Journal of Financial Economics (in press).

Dias, M.A.G. (2004) Valuation of exploration and production assets: An overview of real options models. Journal of Petroleum Science and Engineering, 44, 93-114.

Dias, M.A.G. and Teixeira, J.P. (2004) Continuous-time option games part 2: Oligopoly, war of attrition and bargaining under uncertainty. Working paper, Dept. of Industrial Eng., PUC-Rio, presented at the 8th Annual International Conference on Real Options, Montreal, June 2004. 
Eschenbach, T.G., Lewis, N.A. and Hartman, J.C. (2009) Technical Note: waiting cost models for real options. The Engineering Economist, 54(1), 1-21.

Geske, R. (1979). The valuation of compound options. Journal of Financial Economics, 7, 63-81.

Girsanov, I. V. (1960) On transforming a certain class of stochastic processes by absolutely continuous substitution of measures. Theory of Probability and its Applications, 5, 285-301.

Hendricks, K. and Kovenock, D. (1989) Asymmetric information, information externalities, and efficiency: the case of oil exploration. RAND Journal of Economics, 20, 164-182.

Herath, H.S.B. and Park, C.S. (1999) Economic analysis of R\&D projects: an option approach. The Engineering Economist, 44(1), 1-35.

Herath, H.S.B. and Park, C.S. (2001) Real option valuation and its relationship to Bayesian decision making methods. The Engineering Economist, 46(1), 1-32.

Herath, H.S.B. and Park, C.S. (2002) Multi-stage capital investment opportunities as compound real options. The Engineering Economist, 47(1), 1-27.

Itō, K. (1951) On stochastic differential equations. Memoirs, American Mathematical Society, 4, $1-51$.

Lee, J. and Paxson, D.P. (2001) Valuation of R\&D real American sequential exchang options. $R \& D$ Management, 31(2), 191-201.

Margrabe, W. (1978) The value of an exchange option to exchange one asset for another. The Journal of Finance, 33(1), 177-186.

Marseguerra, G. and Cortelezzi, F. (2010) Strategic investment timing under profit complementarities. Economia Politica, 3, 473-497.

McDonald, R.L. and Siegel, D.R. (1985) Investment and the valuation of firms when there is an option to shut down. International Economic Review, 28(2), 331-349.

Paddock, J., Daniel, S. and Smith, J. (1988) Option valuation of claims on real assets: the case of offshore petroleum leases. Quarterly Journal of Economics, 103(3), 479-508.

Pennings, E. and Sereno, L. (2011) Evaluating pharmaceutical R\&D under technical and economic uncertainty. European Journal of Operational Research, 212(2), 374-385.

Villani, G. (2008) An R\&D investment game under uncertainty in real option analysis. Computational Economics, 32(2-3), 199-219.

Zandi, F. and Tavana, M. (2010) A hybrid fuzzy real option analysis and group ordinal approach for knowledge management strategy assessment. Knowledge Management Research \& Practice, 8 , 216-228.

\section{Appendix A}

This appendix is devoted to the pricing of CEEO and Pseudo Compound American Exchange Option (PCAEO) through Monte Carlo simulations. The typical simulation approach suggests pricing the CEEO and PCAEO as the expected value of discounted cash flows under the risk-neutral probability $\mathbb{Q}$. Therefore, as far as the risk-neutral version of Eqs. (1) and (2), we replace the expected rates of return $\mu_{i}$ by the risk-free interest rate $r$ plus the risk premium, namely, $\mu_{i}=r+\lambda_{i} \sigma_{i}$, where $\lambda_{i}$ is the market price of risk for asset $i=V, D$. Thus, the risk-neutral stochastic equations are as follows:

$$
\begin{aligned}
& \frac{d V}{V}=\left(r-\delta_{v}\right) d t+\sigma_{v}\left(d Z_{v}+\lambda_{v} d t\right)=\left(r-\delta_{v}\right) d t+\sigma_{v} d Z_{v}^{*} \\
& \frac{d D}{D}=\left(r-\delta_{d}\right) d t+\sigma_{d}\left(d Z_{d}+\lambda_{d} d t\right)=\left(r-\delta_{d}\right) d t+\sigma_{d} d Z_{d}^{*}
\end{aligned}
$$

where the Brownian processes $d Z_{v}^{*}=d Z_{v}+\lambda_{v} d t$ and $d Z_{d}^{*}=d Z_{d}+\lambda_{d} d t$ are the new Brownian motions under the risk-neutral probability $\mathbb{Q}$ and $\operatorname{Cov}\left(d Z_{v}^{*}, d Z_{d}^{*}\right)$ is equal to $\rho_{v d} d t$. After some simple substitution and applying Itō's lemma (Itō 1951), we get the 
equation of the simulated price ratio, $P=\frac{V}{D}$, under the risk-neutral measure $\mathbb{Q}$ :

$$
\frac{d P}{P}=\left(-\delta+\sigma_{d}^{2}-\sigma_{v} \sigma_{d} \rho_{v d}\right) d t+\sigma_{v} d Z_{v}^{*}-\sigma_{d} d Z_{d}^{*}
$$

By applying the log-transformation to $D_{T}$, under the probability measure $\mathbb{Q}$, we obtain:

$$
D_{T}=D_{0} \exp \left\{\left(r-\delta_{d}\right) T\right\} \cdot \exp \left(-\frac{\sigma_{d}^{2}}{2} T+\sigma_{d} Z_{d}^{*}(T)\right)
$$

We define $U \equiv\left(-\frac{\sigma_{d}^{2}}{2} T+\sigma_{d} Z_{d}^{*}(T)\right) \sim N\left(-\frac{\sigma_{d}^{2}}{2} T, \sigma_{d} \sqrt{T}\right)$. As a consequence, $\exp (U)$ is $\log$ normally distributed with an expected value, $E_{\mathbb{Q}}[\exp (U)]$, equal to $\exp \left(-\frac{\sigma_{d}^{2}}{2} T+\frac{\sigma_{d}^{2}}{2} T\right)=1$. By Girsanov's theorem (Girsanov 1960), we can define the new probability measure $\tilde{\mathbb{Q}}$ equivalent to $\mathbb{Q}$. The Radon-Nikodym derivative is

$$
\frac{d \tilde{\mathbb{Q}}}{d \mathbb{Q}}=\exp \left(-\frac{\sigma_{d}^{2}}{2} T+\sigma_{d} Z_{d}^{*}(T)\right)
$$

Hence, by using Eq. (A2), we can write:

$$
D_{T}=D_{0} e^{\left(r-\delta_{d}\right) T} \cdot \frac{d \tilde{\mathbb{Q}}}{d \mathbb{Q}}
$$

Moreover, by Girsanov's theorem, the following processes:

$$
\begin{aligned}
& d \hat{Z}_{d}=d Z_{d}^{*}-\sigma_{d} d t \\
& d \hat{Z}_{v}=\rho_{v d} d \hat{Z}_{d}+\sqrt{1-\rho_{v d}^{2}} d Z^{\prime}
\end{aligned}
$$

are two Brownian motions under the risk-neutral probability measure $\tilde{\mathbb{Q}}$ and $Z^{\prime}$ is a Brownian motion under $\tilde{\mathbb{Q}}$ independent of $\hat{Z}_{d}$. By using the Brownian motions defined in Eqs. (A4) and (A5), we can rewrite Eq. (A1) for the asset $P$ under the risk-neutral probability $\tilde{\mathbb{Q}}$, which results in

$$
\frac{d P}{P}=-\delta d t+\sigma_{v} d \hat{Z}_{v}-\sigma_{d} d \hat{Z}_{d}
$$

By simple substitution, we have

$$
\sigma_{v} d \hat{Z}_{v}-\sigma_{d} d \hat{Z}_{d}=\left(\sigma_{v} \rho_{v d}-\sigma_{d}\right) d \hat{Z}_{d}+\sigma_{v}\left(\sqrt{1-\rho_{v d}^{2}}\right) d Z^{\prime}
$$

where $\hat{Z}_{v}$ and $Z^{\prime}$ are two independent processes under the risk measure $\tilde{\mathbb{Q}}$. Therefore, since $\left(\sigma_{v} d \hat{Z}_{v}-\sigma_{d} d \hat{Z}_{d}\right) \sim N(0, \sigma \sqrt{d t})$, we can rewrite Eq. (A6) as follows:

$$
\frac{d P}{P}=-\delta d t+\sigma d Z_{p}
$$

where $\sigma=\sqrt{\sigma_{v}^{2}+\sigma_{d}^{2}-2 \sigma_{v} \sigma_{d} \rho_{v d}}$ and $Z_{p}$ is a Brownian motion under $\tilde{\mathbb{Q}}$. By using the log-transformation, we obtain the equation for the risk-neutral price $P$ :

$$
P_{t}=P_{0} \exp \left\{\left(-\delta-\frac{\sigma^{2}}{2}\right) t+\sigma Z_{p}(t)\right\}
$$


We can now price the CEEO as the expected value of discounted cash flows under the risk-neutral probability $\mathbb{Q}$ and by using $D_{t_{1}}$ as the numeraire, we obtain:

$$
\begin{aligned}
c\left(s, \varphi D, t_{1}\right) & =e^{-r t_{1}} E_{\mathbb{Q}}\left[\max \left(s\left(V_{t_{1}}, D_{t_{1}}, \tau\right)-\varphi D_{t_{1}}, 0\right)\right] \\
& =e^{-r t_{1}} D_{0} e^{\left(r-\delta_{d}\right) t_{1}} E_{\mathbb{Q}}\left\{\max \left[s\left(P_{t_{1}}, 1, \tau\right)-\varphi, 0\right] \frac{d \tilde{\mathbb{Q}}}{d \mathbb{Q}}\right\} \\
& =D_{0} e^{-\delta_{d} t_{1}} E_{\tilde{\mathbb{Q}}}\left[g_{E}\left(P_{t_{1}}\right)\right]
\end{aligned}
$$

where

$$
g_{E}\left(P_{t_{1}}\right)=\max \left\{P_{t_{1}} e^{-\delta_{v} \tau} N\left[d_{1}\left(P_{t_{1}}, \tau\right)\right]-e^{-\delta_{d} \tau} N\left[d_{2}\left(P_{t_{1}}, \tau\right]-\varphi, 0\right\} .\right.
$$

It is possible to approximate the value of CEEO through Monte Carlo simulation as:

$$
c\left(s, \varphi D, t_{1}\right) \approx D_{0} e^{-\delta_{d} t_{1}}\left(\frac{\sum_{i=1}^{n} g_{E}^{i}\left(\hat{P}_{t_{1}}^{i}\right)}{n}\right)
$$

where $n$ is the number of simulated paths and $g_{c}^{i}\left(\hat{P}_{t_{1}}^{i}\right)$ are the $n$ simulated CEEO payoffs.

Along the same line, assuming $D_{t_{1}}$ as the numeraire, we can price the PCAEO as the expected value of discounted cash flows under the risk-neutral probability $\mathbb{Q}$ :

$$
\begin{aligned}
c_{2}\left(S_{2}, \varphi D, t_{1}\right) & =e^{-r t_{1}} E_{\mathbb{Q}}\left\{\max \left[S_{2}\left(V_{t_{1}}, D_{t_{1}}, \tau\right)-\varphi D_{t_{1}}, 0\right]\right\} \\
& =e^{-r t_{1}} D_{0} e^{\left(r-\delta_{d}\right) t_{1}} E_{\mathbb{Q}}\left\{\max \left[S_{2}\left(P_{t_{1}}, 1, \tau\right)-\varphi, 0\right] \frac{d \tilde{\mathbb{Q}}}{d \mathbb{Q}}\right\} \\
& =D_{0} e^{-\delta_{d} t_{1}} E_{\tilde{\mathbb{Q}}}\left[g_{A}\left(P_{t_{1}}\right)\right]
\end{aligned}
$$

where:

$$
\begin{aligned}
g_{A}\left(P_{t_{1}}\right)= & \max \left\{P_{t_{1}} e^{-\delta_{v} \tau} N_{2}\left[-d_{1}\left(\frac{P_{t_{1}}}{P_{2}^{*}}, \frac{\tau}{2}\right), d_{1}\left(P_{t_{1}}, \tau\right),-\rho_{1}\right]\right. \\
& +P_{t_{1}} e^{-\delta_{v} \frac{\tau}{2}} N\left[d_{1}\left(\frac{P_{t_{1}}}{P_{2}^{*}}, \frac{\tau}{2}\right)\right] \\
& -e^{-\delta_{d} \tau} N_{2}\left[-d_{2}\left(\frac{P_{t_{1}}}{P_{2}^{*}}, \frac{\tau}{2}\right), d_{2}\left(P_{t_{1}}, \tau\right),-\rho_{1}\right] \\
& \left.-e^{-\delta_{d} \frac{\tau}{2}} N\left[d_{2}\left(\frac{P_{t_{1}}}{P_{2}^{*}}, \frac{\tau}{2}\right)\right]-\varphi ; 0\right\}
\end{aligned}
$$

and the critical price ratio, $P_{2}^{*}$, that realize the indifference between waiting and investing at the mid-life time, time $\frac{\tau}{2}$, is the solution to the following equation:

$$
P_{2}^{*} e^{-\delta_{v} \frac{\tau}{2}} N\left[d_{1}\left(P_{2}^{*}, \frac{\tau}{2}\right)\right]-e^{-\delta_{d} \frac{\tau}{2}} N\left[d_{2}\left(P_{2}^{*}, \frac{\tau}{2}\right)\right]=P_{2}^{*}-1
$$

If the option $S_{2}\left(V_{t_{1}}, D_{t_{1}}, \tau\right)$ is exercised at time $\frac{\tau}{2}$, we get $\left(V_{\tau / 2}-D_{\tau / 2}\right)$; otherwise, we have an SEEO $s\left(V_{\tau / 2 t}, D_{\tau / 2}, \frac{\tau}{2}\right)$ with a time to maturity $\frac{\tau}{2}$. 
By using Monte Carlo simulation, we can approximate the value of PCAEO as:

$$
c_{2}\left(S_{2}, \varphi D, t_{1}\right) \approx D_{0} e^{-\delta_{d} t_{1}}\left(\frac{\sum_{i=1}^{n} g_{A}^{i}\left(\hat{P}_{t_{1}}^{i}\right)}{n}\right)
$$

where $n$ is the number of simulations. From Eq. (A8), we can observe that $Y=\ln \left(\frac{P_{t}}{P_{0}}\right)$ follows a normal distribution with mean $\left(-\delta-\frac{\sigma^{2}}{2}\right) t$ and variance $\sigma^{2} t$. Therefore, the random variable $Y$ can be generated by $Y=F^{-1}\left(u ;\left(-\delta-\frac{\sigma^{2}}{2}\right) t, \sigma^{2} t\right)$; that is, the inverse of the normal cumulative distribution function, where $u$ is a function of a uniform random variable $U[0,1]$.

\section{Appendix B}

This appendix is devoted to the pricing of simple and compound American exchange options. Carr's $(1988,1995)$ models allow us the evaluate a pseudo-simple American exchange option. Let $t_{0}=0$ be the evaluation date and let $T$ be the maturity date of the exchange option. Let us assume that $V$ and $D$ follow the geometric Brownian motion given by Eqs. (1)-(3) in the text. Carr (1988) showed that the value of a PSAEO $\left(S_{2}\right)$ at time $\frac{T}{2}$ or $T$ is

$$
\begin{aligned}
S_{2}(V, D, T)= & V e^{-\delta_{v} T} N_{2}\left(-d_{1}^{*}, d_{1} ;-\rho_{1}\right)-D e^{-\delta_{d} T} N_{2}\left(-d_{2}^{*}, d_{2} ;-\rho_{1}\right) \\
& +V e^{-\delta_{v} \frac{T}{2}} N\left(d_{1}^{*}\right)-D e^{-\delta_{d} \frac{T}{2}} N\left(d_{2}^{*}\right)
\end{aligned}
$$

where:

- $P=\frac{V}{D} ; \quad \sigma=\sqrt{\sigma_{v}^{2}-2 \rho_{v, d} \sigma_{v} \sigma_{d}+\sigma_{d}^{2}} ; \quad \delta=\delta_{v}-\delta_{d} ;$

- $d_{1} \equiv d_{1}(P, T)=\frac{\log P+\left(\frac{\sigma^{2}}{2}-\delta\right) T}{\sigma \sqrt{T}} ; \quad d_{2}(P, T)=d_{1}(P, T)-\sigma \sqrt{T} ;$

- $d_{1}^{*} \equiv d_{1}\left(\frac{P}{P_{1}^{*}}, \frac{T}{2}\right)=\frac{\log \left(\frac{P}{P_{1}^{*}}\right)+\left(\frac{\sigma^{2}}{2}-\delta\right) \frac{T}{2}}{\sigma \sqrt{\frac{T}{2}}}$

- $d_{2}^{*} \equiv d_{2}\left(\frac{P}{P_{1}^{*}}, \frac{T}{2}\right)=d_{1}^{*}-\sigma \sqrt{\frac{T}{2}} ; \quad \rho_{1}=\sqrt{\frac{T}{2 \cdot T}}=\sqrt{0.5}$;

- $N(d)$ is the cumulative standard normal distribution;

- $N_{2}\left(x_{1}, x_{2} ; \rho\right)$ is the standard bivariate normal distribution function evaluated at $x_{1}$ and $x_{2}$ with a correlation coefficient $\rho$;

- $P_{1}^{*}$ is the unique value that makes it indifferent to exercise the option or not at time $\frac{T}{2}$ and it is the solution to the following equation:

$$
P_{1}^{*} e^{-\delta_{v} \frac{T}{2}} N\left[d_{1}\left(P_{1}^{*}, \frac{T}{2}\right)\right]-e^{-\delta_{d} \frac{T}{2}} N\left[d_{2}\left(P_{1}^{*}, \frac{T}{2}\right)\right]=P_{1}^{*}-1
$$

Moreover, Armada et al.'s (2007) corrected the two-moments extrapolation given in Carr $(1988,1995)$ to approximate the value of a simple American exchange option 
$S(V, D, T)$. By using Armada et al.'s (2007) formula, we have that:

$$
S(V, D, T) \simeq S_{2}(V, D, T)+\frac{S_{2}(V, D, T)-s(V, D, T)}{3}
$$

where $s(V, D, T)$ is the value of a simple European exchange option given by McDonald and Siegel (1985); that is,

$$
s(V, D, T)=V e^{-\delta_{v} T} N\left[d_{1}(P, T)\right]-D e^{-\delta_{d} T} N\left[d_{2}(P, T)\right]
$$

Now, we consider the value of a compound American exchange option whose underlying asset is $S(V, D, \tau)$, the expiration date is $t_{1}$, and the exercise price is a proportion $\varphi$ of asset $D$. By using Armada et al.'s (2007) extrapolation, we can approximate the value of a CAEO as:

$$
C\left[S(V, D, \tau), \varphi D, t_{1}\right] \simeq \frac{4 c_{2}\left[S_{2}(V, D, \tau), \varphi D, t_{1}\right]-c\left[s(V, D, \tau), \varphi D, t_{1}\right]}{3}
$$

where:

- $\tau=T-t_{1}$ is the time to maturity of the SAEO with $t_{1}<T$;

- $c_{2}\left[S_{2}(V, D, \tau), \varphi D, t_{1}\right]$ is the pseudo-compound American exchange option whose underlying asset is the PAEO $S_{2}(V, D, \tau)$ that can be exercised at middle $\frac{\tau}{2}$ and final time $T$;

- the maturity date is the time $t_{1}$;

- the exercise price is a proportion $\varphi$ of asset $D$;

- $c\left[s(V, D, \tau), \varphi D, t_{1}\right]$ is the value of a compound European exchange option whose underlying asset is the simple European exchange option $s(V, D, \tau)$.

The value of PCAEO can be determined using Monte Carlo simulation.

\section{Biographical Sketches}

Flavia Cortelezzi, Ph.D., is Lecturer in Economics at Insubria University. She holds a Ph.D. in Economics and Institutions from University of Bologna and a Master Degree in Economics from Université Catholique de Louvain la Neuve, Belgique. Her research interests include both theoretical and applied research in the fields of industrial and financial economics, with a special focus on investment decisions and decision-making under uncertainty. She is currently looking at the way social capital influences investment in R\&D.

Giovanni Villani, Ph.D., is Lecturer in Mathematical Methods for Economics and Finance at University of Foggia. He holds a Ph.D. in Mathematics Methods for the Economic and Financial Decisions. His current research fields are focused on the valuation of $R \& D$ real options, the Monte Carlo approach to solve option pricing and the stability of International Environmental Agreements using the Game Theory. 